\title{
Time-based management concept on the basis of the organizational-managerial innovations in a logistic company
}

\author{
Lubov Shamina ${ }^{1 *}$, and Iolanta Borisova ${ }^{2}$ \\ ${ }^{1}$ St. Petersburg Branch of the Financial University under the Government of the Russian Federation, St. \\ Petersburg, 197198, Russia \\ ${ }^{2}$ ITMO University, Kronverksky pr. 49, St. Petersburg, 197101, Russia
}

\begin{abstract}
Time could be considered as an important competitive advantage of logistics companies. In fact, execution time is the most significant factor affecting the performance of the supply chain. Regarding the issue mentioned above, it seems relevant to develop the economic and organizational-managerial paradigm from value-based thinking to a timebased. The focusing on the reducing the time cycle suspends the competitive advantage, received by the logistics company due to the shortening response time for customer requests. Therefore, we have set the time factor in the basis of the logistics company performance appraisal and the main effort should be focused on reducing the delivery time cycle from the moment of the order receipt to its final delivery to the consumer.
\end{abstract}

\section{Time expenditure in the concept of innovation management}

IT solution innovative concept effectiveness is considered by prof. I. Ilin [3] as well as the prof. O. Kalinina innovative approach to progressive scale taxation developed for macroeconomic social orientated models [4]. Undoubtedly the significant attention is paid to the issues of innovative development of the transport strategy, which reflects the relevance of the topic of the article to the trend that there was a positive dynamics in the development of the transport sector despite the current conditions for the external economy changing and reducing the volume of financing [2]. The authors examine the essence of the innovative option aimed at observing ecological parameters and energy efficiency indicators of transport. It is pointed out that such an option should be based on the implementation of technological product and process innovations. The author's position considers that the basic object of research is the process of implementing technological innovations in the field of ecology and energy efficiency of the transport complex.

The problem of raw products, materials and goods prompt delivery from one part of the planet to another remains relevant. The logistic company clients are strictly dependent upon the quality of the services provided; their profits are directly directed by their terms and quality of goods delivery to their customers. The logistics company does not only provide services, it affects many supply chains from producers to end-users for different products. In

*Corresponding author: 1kshamina@rambler.ru 
fact the logistics company is an important element in the economics. It should take a long period of time for scientists to work in the field of logistic business processes improvement, so that the future economic world can reckon on ultra-technologies that ensure its sustainable development in modern unstable world. In the future this could be the superfast and, perhaps, instant technology of product logistics from one part of the world to another.

Time could be considered as an important competitive advantage of logistics companies. In this regard, it seems relevant for us to change the economic and organizational-managerial paradigm from value-based thinking to a time-based. Therefore, we have set the time factor in the basis of the logistics company performance appraisal and the main effort should be focused on reducing the delivery time cycle from the moment of the order receipt to its final delivery to the consumer. At the same time, reducing the delivery time cycle gives competitive advantages, tends to costs reduction (burden charges) and leads to improvement regarding the quality of the logistics services (as the reducing the delivery time cycle assumes identifying and eliminating bottlenecks that slow down the delivery process). Further in the article, we are considering the possibility to shorten the time cycle of the products transfer to the final consumer (for example, the delivery of goods from Livorno (Italy) to Novosibirsk (Russia)).

Large number of companies used to have an unalterable opinion that there is a need to order the goods as early as possible in order to provide a supplier with enough time to perform the logistical operations. In return, suppliers force customers to place an order earlier and with detailed forecasting.

The competitive advantage, received by the logistics company as a result of the reducing the time cycle, is conditional on the fact that the response time for customer requests is shortened too. For the logistics company itself this means the opportunity to increase the number of orders. For customers this means the ability to minimize their stock reserves, what leads to driving down costs.

In fact, a longer delivery time implies exigency to hold more stock reserves and to stay under increased risk of raw materials shortage. At the same time a large stockings quantity makes it difficult to introduce new products or respond to market changes. This factor also intensifies the consequences of problems related to product quality, since by the time the problem is discovered (or occurred) the product may be under the process of the delivery from the supplier. The goods flow has already affected the accounting and financial reporting. And the longer the delivery time, the more losses the customer suffers.

All problems with a long delivery time are offset by the distance and the general mistaken belief that there is no possibility for faster delivery.

In real life the actual delivery time of goods from one part of the world to another is relatively small compared to the time that most suppliers add to the delivery process. The table (Table 1) below shows the actual delivery times for a number of common routes:

Table 1. Terms of products delivery on common routes

\begin{tabular}{|c|c|c|c|c|c|}
\hline Departure port & Destination port & $\begin{array}{c}\text { Load time, } \\
\text { days }\end{array}$ & $\begin{array}{c}\text { Delivery time, } \\
\text { days }\end{array}$ & $\begin{array}{c}\text { The unloading and } \\
\text { delivery time, days }\end{array}$ & $\begin{array}{l}\text { Total execution } \\
\text { time, days }\end{array}$ \\
\hline Shanghai & Melbourne & 2 & 13 & 3 & 18 \\
\hline Shanghai & Hamburg & 2 & 25 & 3 & 30 \\
\hline Shanghai & Los Angeles & 2 & 13 & 3 & 18 \\
\hline Rotterdam & Melbourne & 2 & 37 & 3 & 42 \\
\hline Felkstov & Singapore & 2 & 21 & 3 & 26 \\
\hline
\end{tabular}

The table shows that the longest lead time is about seven weeks, and most routes from Asia take from two to four weeks. Therefore, the delivery time does not explain the excessively long delivery times that many suppliers and logistics companies declare. 


\section{The transportation solutions techniques in time-based thinking management}

The delivery time managing calls for setting apart the productive and non-productive time losses with focusing on the delay reasons identification and ways of non-productive losses eliminating. Some of problems can add a few days, and some may add a few weeks. In terms of time-based thinking these delays are all waste products of the production process and all of them are inevitable.

The consciousness of the process content, that includes the calculations of the product delivery route from the supplier to the consumer, helps to identify problems and shorten the delivery time. There are many reasons for non-productive time losses. Some of them:

Delays in the order processing occurred in the logistics business, especially when staff is aimed for long order cycles, such as a quarterly order or an attempt to artificially created large order to obtain a lower delivery price. Usually, small orders are combined into a combined one, which takes a lot of time. These losses can be up to three months.

Delays in the order processing by the supplier. From several hours to several weeks.

Suppliers, who wait for an order before starting the materials procurement. This fact doubles the execution time, because the customer is forced to wait for the supplier to confirm readiness for goods shipment. Only when it has been approved by the initial supplier, they will start to work directly on the goods delivery. Poor production management from supplier's side. Decisions to set the order for a low priority.

Low business processes quality by the supplier, leading to a long internal execution time (in other words, the supplier needs to apply time-based thinking)

Delays starting after the finish of the goods production (waiting time for transportation to the supplier's warehouse, for example, to/from the port, combination with other containers, allowance to be loaded on the ship). Usually this delay occurs at the supplier's production warehouse.

Freight forwarder delays or delays in the port while waiting for loading onto the ship.

Delays that occur due to the use of indirect delivery routes, when ships stop at several ports and goods are even reloaded in intermediate ports from one ship to another.

Stevedore delays at the receiving port waiting for unloading, cross-docking or delivery.

Reducing the product supply time cycle involves a number of actions:

1. listing of the involved in the order fulfillment executors;

2. the delivery process description;

3. the total time calculation for execution of each operation in the delivery process;

4. evaluation of the real time for order execution;

5. the order execution card creation (with full and real-time delivery of the order);

6. the determination of time loss causes and the development of measures to eliminate them.

In this article we will consider an example of product delivery from Italy (Livorno) to Russia (Novosibirsk). It all starts with the fact that the logistics company receives a request for delivery of an especially dangerous first class cargo from Italy to Novosibirsk by road (shade-shed $92 \mathrm{~m} 3,20$ tons) to the state defense enterprise from the governmental customer. The client is ready to pay a 50\% prepayment after signing the Contract within 3 banking days. The balance will be paid after the car arrives in Novosibirsk.

Shipping documents have already been issued by the relevant services of the Italian manufacturer. Client has to receive import and export licenses for this product independently. It takes 1 week. Client is to provide armed escort and to execute the special permit for transportation on the territories of the Russian Federation and Belarus. The logistics company received the order in mid-June, and this project must be completed by mid-August, as in August the rainy season starts and the roads can be blurred at some parts of the route. 
Taking into account the order processing by the manager, we have the time for the order start of 60 days, another 15 days the shipper spent on agreeing the cost of the contract and preparing the necessary documentation. At the same time, the cargo had already been ready since July. In actual fact the carrying cargo car was able to leave for Italy only in early September. It took so long for the manager and contractors to find the right transport. This delay includes time that the logistic companies used to calculate the costs for the cargo transfer and at the same time to collect the necessary permits for the car. The order was completed by the end of September because of the small blurring of roads, the company recorded a profit on the transaction of 8500 euro taking into account the total cost of the order 28500 euro.

Now let us consider the components of the time cycle for this transfer order:

1. Listing of the involved in the order fulfillment executors:

the logistics company manager, the company-carrier manager, car driver, the customer's manager (composes and collects a significant part of documents for this order), the consignee manager.

2. The delivery process description

Import and export licenses for this product are received by customer's manager. In addition, this manager makes transportation documents, an international consignment note (CMR), a packing list, an invoice, a description, a safety data sheet, an export declaration and other required documents. Contracts and applications between the logistics company and the customer are signed, as well as between the logistics company and the carrier. The carrier receives the necessary permits in the international association ASMAP, in this case it will be a tripartite solution between Slovakia, Italy and Russia as the carrier company is situated in Slovakia and uses the vehicles registered in this country. The carrier's manager also obtains a transit declaration on the territory of Belarus and Russia.

The logistics company provides protection and escort of cargo on the territory of Belarus and Russia, this service is paid by the consignee.

The transportation process is: the car is loaded in Livorno, the driver receives the above mentioned set of documents. After that the route passes through Brest (Belarus), where is a border crossed and then the cargo is escorted to the place of customs clearance in Novosibirsk, and finally transported to the unloading place in Novosibirsk. He also carries out a photo report of loading and unloading processes.

3 . The total time calculation for execution of each operation in the delivery process provided that the goods are ready for shipment when the application is received by the logistics company

The supplier search takes 2-3 days as a rule, but the manager of the logistics company spent 2 months searching due to the fact that he had 3 more orders in process at the same time. These projects were partially finished and some of them were processed with delay. If he concentrated his efforts on the realization for Livorno-Novosibirsk delivery and was not distracted by other orders, he could organize the cargo shipment in July, thus the company would bank profits in July and the manager could take on the next order and start it in August.

- Permits collection and issuance of documents by the customer - 3 days

- Contracts and applications execution- 2 days

- Tripartite approval obtaining from the side of the carrier - 1 day

- Loading - 1 day

- Delivery from Livorno to Novosibirsk - 10 days, customs clearance and unloading - 2 days.

4. Evaluation of the real time for order execution (when the order is currently in progress) -23 days.

5. The order execution card creation (with full and real-time delivery of the order) (Table 2, Fig.1) 
6. The determination of time loss causes and the development of measures to eliminate them. Analysis of this situation revealed the following reasons for the loss of time:

- the logistics company manager workload;

- the registration of contracts and documentation was delayed due to the office protraction, that could also be reduced by 1-2 days by operating with working time more efficiently.

Table 2. Order execution card (Livorno - Novosibirsk)

\begin{tabular}{|r|l|c|c|}
\hline No & Transaction name & Real time, days & Spent time, days \\
\hline 1 & Carrier search & 3 & 68 \\
\hline 2 & Contract execution & 2 & 3 \\
\hline 3 & Document execution & 3 & 4 \\
\hline 4 & Obtaining a permit & 1 & 1 \\
\hline 5 & Loading & 1 & 1 \\
\hline 6 & Transportation & 10 & 10 \\
\hline 7 & Custom clearance & 2 & 2 \\
\hline 8 & Unloading & 1 & 1 \\
\hline Total & & 23 & 90 \\
\hline
\end{tabular}

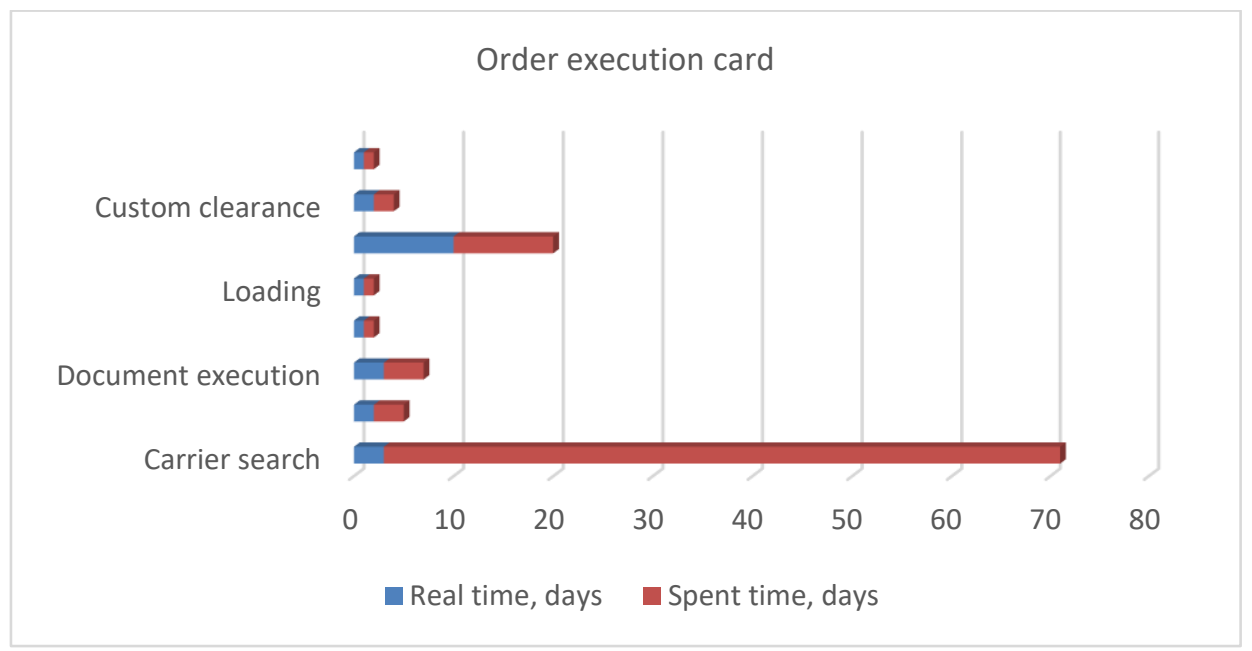

Fig. 1. The ratio of real and spent time for the order execution

\section{The time-based thinking model}

Measures to eliminate the loss of time could differ in dependence with the situation. Logistics company manager must be focused on the singular order to finish the carrier searching on time. The manager of the logistics company should use the time-based thinking himself and at the same time control the shipper to execute a set of documents for the driver on time. Also, the carrier's manager must obtain a tripartite permission on time and execute the relevant documents. As a result the time cycle took three months, though it could be reduced according to the next value:

2 days for the search of a carrier and the agreement of terms, 2 days for signing the contract, 2 weeks for obtaining the necessary permits, 2 days for a car to come from Slovakia for loading in Livorno, 1 day for loading, 10 days the car is on the road before unloading, 2 days are for custom clearance and unloading. 33 days in total, and then the company can bank profits in July; the manager has an ability to start another project. Take notice that the 
company did not bear any additional costs to reduce the time cycle of the order with the only one change: correctly placed priorities in the fulfillment of tasks.

Despite the decision to turn for a time-based thinking, an estimate of these costs must be held. The rule "Power of Six" by Suri set an indicator that managers can follow when deciding on the implementation of time-based thinking in the organization.

This rule can be used in the following situations:

The management sets a goal to achieve a certain reduction in costs to win a competitive struggle by means of low prices. For this purpose the certain period of time, which allows arriving at a goal, must be set as target.

If you raise the target cost factor to the sixth power, you get the target ratio for the order process time. Thus, the practical rule of the "Power of Six" helps to set a defined goal.

According to the rule "Power of Six" by Suri [1]:

$$
M R=\frac{\text { Target } \mathrm{CPR}}{\text { Current } \mathrm{CPR}}
$$

where MR is the critical production ratio for the service (in fact the order cycle); the expected target CPR equals to 33 days, and the current CPR is taken as 90 days.

$$
\begin{gathered}
M R=\frac{33}{90}=37 \% \\
C R=M R^{1 / 6}
\end{gathered}
$$

where, $\mathrm{CR}$ - cost ratio.

The production cycle decreasing by $37 \%$ leads to a significant reduction of costs. Organization employees are able to determine the potential for a significant reduction in the order execution cycle, but then the management's consent for project investment must be obtained. For this purpose the cost reduction must be pointed out as the result of the project.

\section{Conclusion}

In fact, execution time is the most significant factor affecting the performance of the supply chain. The time-based approach specified above is based on the concept of searching for unproductive time and focuses on reducing the entire time of the order fulfillment. This is accompanied by the following regularity: when the time cycle is shortened, the reduction of total costs also decreases. Thus, we can talk about reducing the time cycle from the order receipt to its delivery to the consumer as the systemic process, which includes reduction of the total costs, quality improvement of the provided services and shortening the time of order receipt.

\section{References}

1. Rajan Suri. It's About Time: The Competitive Advantage of Quick Response Manufacturing. (USA, Productivity Press, 2010)

2. Shamina L.K. Proc. of the scientific-practical conf. with international participation. Conf. Papers. SPbPU. 2017. DOI: 10.18720/IEP/2017.5/48

3. I. Ilin, S. Shirokova, A. Lepekhin, E3S Web of Conferences 33 (2018)

4. Kalinina, O.V. Universal approach to building the progressive scale for income taxation. Actual Problems of Economics, 387 - 400 (2016) 